\title{
Vorwort zur einundzwanzigsten Auflage
}

Der rasche Absatz der letzten Auflage machte vorübergehend einen unveränderten Nachdruck notwendig, dem nunmehr die 21., sorgfältig durchgesehene und in mancher Hinsicht erweiterte Auflage folgt. Es bedarf keiner Begründung, daß das immer noch in rascher Entwicklung begriffene Gebiet der Naturstoffe hierbei in erster Linie berücksichtigt wurde. So sind die Abschnitte Fette, Kohlenhydrate, Eiweißstoffe, Enzyme, Sterine, Vitamine, Pyrrolfarbstoffe und Alkaloide entsprechend dem Stand der Forschung teilweise neu bearbeitet und in größerer Ausführlichkeit behandelt worden. Aber auch viele den einfacheren Verbindungen gewidmete Artikel haben diesmal durch größere oder kleinere Änderungen eine reichere Ausgestaltung erfahren. Die Neuaufnahme einer verhältnismäßig beschränkten Anzahl von Verbindungen und Reaktionen, die in gleicher Weise dem Interessenkreis der reinen Chemie, der Biochemie und der chemischen Technik entstammen, erlaubte in vielen Fällen eine abgerundetere Dar. stellung des Verhaltens der einzelnen Körperklassen. Schließlich wurden auch die theoretischen Kapitel sorgfältig überarbeitet und nach Möglichkeit durch Beispiele im Sinn neuerer Anschauungen ergänzt. Die durch viele Auflagen bewährten Grundsätze der Einteilung und Stoffbehandlung habe ich im wesentlichen beibehalten. Sie werden im Verein mit der reichlichen Verwendung von Kleindruck der doppelten Auf. gabe dieses Lehrbuchs dienlich sein, dem Anfänger die Kenntnis der Grundlagen zu vermitteln und den Fortgeschrittenen auf die Probleme der Gegenwart vorzubereiten. Zahlreichen Fachgenossen bin ich für Rat und Anregung zu Dank verpflichtet, so insbesondere den Herren Prof. Butenandt und H. Frscher für freundliche Durchsicht der Kapitel Sterine und Pyrrolfarbstoffe. Besonderer Dank gebührt schließlich auch dem Verlag, der trotz der schwierigen Zeiten Kosten und Mühe eines Neusatzes nicht scheute, um durch ein handliches und übersichtliches Format die Brauchbarkeit des Buches zu erhöhen.

Berlin, im Dezember 1939.

Friedrich Richter

\section{Vorwort zur sechsundzwanzigsten Auflage}

In nicht abreißendem und fast unübersehbarem Strom ergießen sich seit einigen Jahren die Forschungsergebnisse der Kriegs- und Nachkriegszeit in die wissenschaftliche Literatur. Der Zuwachs an Kenntnissen ist auch bei zurückhaltender Beurteilung achtunggebietend, die damit verbundene Weitung des allgemeinen Gesichtskreises nicht minder eindrucksvoll. Die 26. Auflage sucht dem bei zunächst noch unveränderter Anlage Rechnung zu tragen und ist wieder sorgfältig dem Stand der Forschung angepaßt. Fast auf jeder Seite wird der aufmerksame Leser entsprechenden Ergänzungen oder Änderungen begegnen. Sie erstrecken sich ebensowohl auf die organische Chemie klassischer Prägung, die mit der ihr eigenen Methodik und Intuition das Feld in unverminderter Lebenskraft beherrscht, wie auf ihre Verknüpfung mit physikalischtheoretischen und biochemischen Beziehungen, aus denen sie ständig neue Impulse von steigender Wichtigkeit erhält. Daß das Lehrbuch im vergangenen Jahr auf das nicht gerade häufige Ereignis eines 50 jährigen Bestehens zurückblicken konnte, verdankt es wohl vornehmlich eben der Betonung des Grundsätzlichen und dem Streben nach Ein- 
heit der theoretischen Vorstellungen, auf denen das Wundergebäude der organischen Strukturchemie ruht. Kein Erbe, dessen Besitz nicht auch hier ständig neu erworben werden müßte. Der große Wandel in den Verfahren der Technik hat in der vorliegenden Auflage gleichfalls in vielen Beispielen seinen Niederschlag gefunden.

Wie in den Vorjahren bin ich auch diesmal zahlreichen Fachgenossen, unter denen ich besonders Herrn Prof. Отто BAYER hervorheben möchte, für wertvolle Ratschläge und Auskünfte zu Dank verpflichtet.

Frankfurt a. Main, im Oktober 1949.

Friedrich Richter

\section{Vorwort \\ zur neunundzwanzigsten und dreißigsten Auflage}

Dem raschen Fortschritt der Forschung auf den meisten Gebieten der organischen Chemie wurde in der vorliegenden Ausgabe wiederum durch eine sorgfältige Durchsicht Rechnung getragen, von der kaum eine Seite unberührt geblieben ist. Durch Verzicht auf älteres, heute didaktisch weniger ergiebig erscheinendes Material konnte ein stärkeres Anschwellen des Textes vermieden und Platz für neue Ergebnisse gewonnen werden. Daß auch so Rücksichten auf Umfang und Ausgabetermin manche Beschränkungen erforderten, versteht sich bei der Fülle des Materials von selbst. Unter den größeren Erweiterungen dieser Auflage sei namentlich das Alkaloid-Kapitel hervorgehoben, das durch Abschnitte über Mutterkorn- und Steroid-Alkaloide sowie über die Synthese des Morphins bereichert wurde. Mehrfachen Anregungen folgend habe ich mich entschlossen, diesmal auch eine zusammenhängende Darstellung der chemischen Nomenklatur in ihren Grundzügen zu bringen. Obwohl der durch den Umfang des Lehrbuchs gezogene Rahmen naturgemäß ein Eingehen auf viele Einzelheiten verbot, hoffe ich doch, daß die hier gegebene Utbersicht Wesentliches zum Ausdruck bringt und dadurch den Zugang zu diesem schwierigen Gebiet erleichtern wird. Mein Dank gilt wie stets den Fachgenossen und Studenten, die durch Ratschläge oder Hinweise zur Verbesserung dieser Auflage beigetragen haben.

Frankfurt-Höchst, im April 1953.

Friedrich Richter

\section{Vorwort \\ zur einunddreißigsten und zweiunddreißigsten Auflage}

Trotz der kurzen seit der letzten Auflage verflossenen Zeitspanne machte der Fort. schritt der Forschung im Grundsätzlichen und in der Vielfalt der Erscheinungen, aus denen gemeinsam sich erst das volle Bild der organischen Chemie rundet, wieder zahlreiche Verbesserungen und Ergänzungen möglich. Der Begründer des Lehrbuchs, A. F. HollemaN, bekannt vor allem durch seine Forschungen auf dem Gebiet der Benzolsubstitution und der Prototropie der Nitroverbindungen, verstarb am 11. August $1953 \mathrm{im}$ hohen Alter von 94 Jahren. Sein Andenken lebt in dem Lehrbuch weiter, dem er bis in die letzte Zeit sein Interesse bewahrt hatte.

Frankfurt-Höchst, im Juli 1954. 